\title{
PERCEPÇÃO DE TEMPO E NECESSIDADE DE ATIVIDADE NA SOCIEDADE DO EXCESSO: EDUCAÇÃO NO CONTEXTO DAS TECNOLOGIAS DIGITAIS
}

\author{
PERCEPTION OF TIME AND NEED FOR ACTIVITY IN SOCIETY OF EXCESS: \\ EDUCATION IN THE CONTEXT OF DIGITAL TECHNOLOGIES
}

\section{PERCEPCIÓN DEL TIEMPO Y NECESITAD DE ACTIVIDADES EN LA SOCIEDAD DEL EXCESO: EDUCACIÓN EN EL CONTEXTO DE LAS TECNOLOGÍAS DIGITALES}

\section{Hamilton Viana Chaves ${ }^{1}$ Osterne Nonato Maia Filho ${ }^{2}$}

\begin{abstract}
RESUMO: O contexto educativo promovido pelas tecnologias digitais tem sido objeto de investigação de inúmeros pesquisadores. Abordam o tempo diminuto com que as informações circulam e a quantidade expressiva de atividades humanas supostamente facilitadas pelas tecnologias digitais. Como se daria, então, a relação entre percepção temporal e necessidade de atividade no processo educativo face à sociedade do excesso? Este artigo tem por objetivo discutir esta questão uma vez que se trata de um fato por vezes minimizado pelas pesquisas que abordam o uso das tecnologias de informação e comunicação na educação. Foi feita uma revisão narrativa da literatura e seu cotejo com nossa prática educativa nas condições de psicólogos de uma instituição de educação profissional e tecnológica e professores do magistério superior. Consumo de marcas, formação continuada, produtivismo no trabalho e redução da experiência subjetiva são formas de lidar com a emergente necessidade de atividade na sociedade do excesso. Nossas análises indicam que existe uma percepção de tempo comprimida, o que deporia contra uma urgente e ampliada necessidade de atividade fruto de uma sociedade do excesso. Tal situação exigiria dos profissionais da educação uma revisão de suas práticas pedagógicas no sentido minimizarem os efeitos da compressão temporal.
\end{abstract}

PALAVRAS-CHAVE: Percepção de tempo. Educação. Tecnologias digitais.

\begin{abstract}
The educational context created by digital technologies has been the subject of numerous researchers, which concerns to the small amount of time that information flows and the significant amount of human activities that are allegedly facilitated by digital technologies. How could it be, then, the relationship between perception of time and need for activity in the educational process before the society of excess? This article aims to discuss these issues since it is about a fact that, sometimes, is minimized by researches about the use of information and communication technologies in education. It has been made a narrative review of the literature and its comparison with our educational practice as psychologists and teachers of a professional and technological education institution. Consume of various brands, continuing education, high productivity at work and reduction of the subjective experience are ways to deal with the emerging need for activity in the society of excess. Our analyzes indicates that there is a compressed perception of time, which could be against an urgent and amplified need for activity that results of the society of excess. Such situation would require of the education professionals a review of their teaching practices to minimize the effects of temporal compression.
\end{abstract}

KEYWORDS: Primeira palavra. Time perception. Education. Digital technologies.

\footnotetext{
${ }^{1}$ Doutor em Educação pela Universidade Federal do Ceará - UFC, Fortaleza, CE - Brasil. Psicólogo do Instituto Federal de Educação, Ciência e Tecnologia do Ceará; Professor do curso de Psicologia da Universidade de Fortaleza, UFC, Fortaleza, CE - Brasil. E-mail: hamilton@unifor.br.

${ }^{2}$ Doutor em Educação pela Universidade Federal do Ceará - UFC, Fortaleza, CE - Brasil. Professor Doutor da Universidade Federal do Ceará e da Universidade de Fortaleza, CE - Brasil. E-mail: osterne_filho@uol.com.br.

Recebido em: 05/06/2015 - Aprovado em: 18/03/2015.
}

\begin{tabular}{l|l|l|l|l|l|l} 
(C) ETD -Educ. Temat. Digit. & Campinas, SP & v.18 & n.1 & p. 71-82 & jan./abr. 2016 & ISSN 1676-2592
\end{tabular}


RESUMEN: El contexto educativo promovido por las tecnologías digitales han sido objeto de investigación de distintos pesquisidores. Abordan la velocidad con que las informaciones circulan y la cantidad expresiva de actividades humanas supuestamente facilitadas por las tecnologías digitales. ¿Cómo sería, entonces, la relación entre la percepción temporal y necesidad de actividades en lo proceso educativo en frente la sociedad del exceso? Este artículo tiene por objetivo discutir esta cuestión una vez que se trata de un hecho por veces minimizado por las pesquisas que abordan la utilización de las tecnologías de información y comunicación en la educación. Se hizo una revisión narrativa de la literatura y su confrontación con nuestra práctica educativa en las condiciones de psicólogos de una institución de educación profesional y profesores de la docencia universitaria. Consumo de marcas, formación continua, productivismo en el trabajo y reducción de la experiencia subjetiva son maneras de hacer frente a la emergente necesidad de actividades en la sociedad del exceso. Nuestros análisis indican que hay una percepción de tiempo comprimida, lo que testificaría contra una urgente y ampliada necesidad de actividades resultadas de una sociedad del exceso. Tal situación requeriría de los profesionales de educación una revisión de sus prácticas pedagógicas en lo sentido de minimizar los efectos de la compresión temporal.

PAlabras ClaVE: Primeira Percepción del tiempo. Educación. Las tecnologías digitales.

\section{INTRODUÇÃO}

Diversos pesquisadores têm envidado esforços na tentativa de analisar os impactos da utilização das tecnologias digitais aplicadas à educação (MOURA; SOUZA, 2014; PERROTA, 2014). Dá a impressão de haver uma propensão em avaliar apenas os benefícios que essas tecnologias, sob o gênero de informação e comunicação, propiciam à formação humana e ao processo de ensino e de aprendizagem.

Destacam, por exemplo, a maior fluidez possível do conhecimento e sua democratização, propiciadas pela acessibilidade em redes com fins à autonomia daqueles que aprendem (TRIGANO, 2006; POZO, 2005). Um dos intentos da educação, neste contexto, seria aquilo que Zimmerman (1990) denomina aprendizagem autorregulada. Diz respeito à aquisição de informações e desenvolvimento de habilidades as quais envolvem uma agenda definida, objetivos delimitados e percepção consciente do objeto de estudo. Em um sentido mais amplo, corresponde ao próprio desenvolvimento do sujeito, não se limitando ao psiquismo, haja vista que sua história evolutiva, em termos ontogenético, filogenético e sociogenético correspondem a uma contínua e dialética evolução por meio da autorregulação da conduta (VYGOTSKI, 2000).

Parece ser indubitável que este contexto educativo estaria acintosamente marcado por uma particular configuração de temporalidade e de espacialidade (TSATSOU, 2009). Nos termos de Harvey (2000), estamos experimentando uma compressão tempo-espaço dado à conjuntura de globalização e às novas formas de experiências subjetivas que as sociedades contemporâneas propiciam. Em outra oportunidade avaliamos este impacto nas relações de produção ao longo da história (MAIA FILHO; CHAVES; RIBEIRO; SOUSA, 2014). Naquele momento, atentamos principalmente para essa experiência eminentemente humana, especialmente no modo de produção capitalista, e suas consequências para as relações sociais. Na atual oportunidade, nos perguntamos: como se daria a relação entre percepção temporal e necessidade de atividade no processo educativo da sociedade atual, que estamos chamando de sociedade do excesso, por falta de conceito mais preciso? Ressalte-se que estamos demarcando as categorias necessidade de atividade e sociedade do excesso em sua relação com a percepção de tempo. 
Necessidade de atividade diz respeito à experiência subjetiva de atender às supostas demandas delimitadas pela sociedade contemporânea. Sociedade do excesso contextualizaria a abundância de demandas e atividades característica da sociedade atual. Nesse sentido, estas podem se apresentar pelo consumo de marcas (SEVERIANO, 2007), pela constante necessidade de formação continuada (VEEN; VRAKKING, 2006), pelo aumento da produtividade no trabalho (HARVEY, 2000) ou simplesmente pela redução da experiência subjetiva ao universo dos aparelhos (FLUSSER, 2010).

Esta discussão nasceu do propósito particular dos autores em rever suas próprias condições de sujeitos e agentes da educação, uma vez que são psicólogos de uma instituição de educação profissional e tecnológica e professores do magistério superior. Devido a esta motivação, realizamos uma revisão narrativa da literatura que corresponde, segundo Cordeiro, Oliveira, Rentería e Guimarães (2007), a um tipo de seleção arbitrária de textos dominada pela percepção subjetiva dos pesquisadores e que, em suas perspectivas podem contribuir para a produção de novas zonas de sentido (REY, 2002).

Após a seleção e exploração do material bibliográfico, procedemos ao cotejo do resultado da revisão com nossa prática cotidiana ligada ao contexto educacional. Tal estratégia teve como objetivo ilustrar alguns argumentos centrais desenvolvidos ao longo deste ensaio teórico nos termos propostos por Adorno (1994), na medida em que se é livre para a escolha de seu objeto de análise, pondo em relevo que tal objeto é historicamente situado. O ensaísta não se limita aos dados e verdades já produzidos, mas os coloca em questionamento na busca de produzir novas elaborações. Também não se ilude com a falsa separação entre ciências da natureza e ciências humanas.

\section{TEMPORALIDADE, ATIVIDADE E EXCESSO}

A utilização de recursos materiais na educação tem um propósito similar ao campo metonímico-metafórico, isto é, predomina o indiciário e o figurativo, os quais correspondem à ampliação da capacidade de explicitação de conhecimento para além do discurso falado. Quando as palavras faltam ou parecem limitadas, faz-se a utilização recursiva de materiais no intuito de facilitar o processo educativo. São as tecnologias que paradoxalmente entraram no espaço escolar desde as mais tenras experiências, entre outras tentativas de suprir estes espaços. Aliás, a própria utilização do termo tecnologia já remete, segundo Castoriadis (1987), a uma metáfora, ou melhor, a uma metonímia, uma espécie de metáfora embrionária e indiciária (PEIRCE, 1999), haja vista que a tecnologia é a ciência da técnica, ou ciência em extensão (nada mais metonímico-metafórico). Na verdade, do que os educadores se valem é de recursos técnicos que facilitariam o compartilhamento e a troca do conhecimento, processo recorrentemente chamado metonimicamente pela cultura de transmissão do conhecimento em vista da sofreguidão social de garantir às novas gerações a apreensão de suas experiências acumuladas em uma tradição, quase como faz o aedis aegypti ao funcionar como vetor de diversos vírus.

É bem mais recente a utilização de recursos técnicos sustentados pela lógica binária e materializados pela eletrônica digital (SCHAFF, 1990). A abrangência e popularização dos 
dispositivos eletrônicos, antes restritos aos mais importantes centros universitários e à pasta militar, ganhou profusão nas mais diversas camadas populares adentrando, inclusive, à escola básica. Tal situação seria responsável por uma nova forma de experimentação subjetiva da realidade, principalmente no que diz respeito à vivência da experiência temporal, inclusive da aprendizagem (CHAVES; MEDEIROS, 2010) que decorreria de uma nova forma de estruturação da sensação humana (TÜRCKE, 2014).

Para Harvey (2000), as atuais condições sociais nomeadas por muitos, como pós-modernas, corresponderia ao que ele categorizou como acumulação flexível do capital, e estaria na raiz de uma compressão tempo-espaço que, por sua vez, diz respeito a experiências subjetivas de experimentação temporal e espacial face aos contextos objetivos de velocidade na circularidade da informação, fluidez do deslocamento do capital e esmaecimento das fronteiras geográficas com uma suposta formação de uma aldeia global. Tsatsou (2009) denomina mediada esta configuração desenhada por Harvey (2000), uma vez que, para aquela autora, as relações sociais seriam significativamente facilitadas pelas novas estratégias de acesso à informação e à comunicação, provocadas pelo contexto das tecnologias digitais.

Este último argumento, ao que nos sinaliza, merece um tratamento mais cuidadoso, uma vez que se inseriria na perspectiva de determinadas pesquisas que sobrestimariam os recursos tecnológicos aplicados à educação, ao mesmo tempo em que quase são furtivos os indicativos de suas limitações, tais como em Trigano (2006), Moura e Sousa (2014), Perrota (2014), entre outros.

Moura e Souza (2014) parecem ser taxativos quando afirmam que as novas tecnologias transformariam, de modo significativo, a comunicação, as relações interpessoais, o trabalho, o que incluiria as tomadas de decisões e formas de pensamento. Argumento que encontraria ressonância na perspectiva de Perrota (2014) quando afirma que a percepção dos educadores sobre possíveis benefícios de tais tecnologias dar-se-ia conforme um forte elo de perspectivas entre professores e gestores de escolas. Trigano (2006) ressalta que os usos dessas tecnologias reforçariam componentes cognitivos e motivacionais, embora avente para o fato de que os recursos tecnológicos não poderiam ser tomados como um fim em si mesmos.

A esse respeito, quando realizamos uma análise mais crítica dos impactos da aceleração tempo-espaço nos modos de produção (MAIA FILHO, CHAVES, RIBEIRO, SOUSA, 2014), sobretudo no atual modo, o capitalista, verificamos que a contemporânea situação estaria marcada também pela desterritorialização, pela descontextualização e alienação temporal, o que poderia se reverter em sofrimento psíquico e no esgarçamento das relações sociais, portanto produzindo outros efeitos para além das relações produtivas.

Nesta oportunidade nos valemos da mesma perspectiva crítica de outrora, mas dedicamos nossos esforços aqui especificamente à análise dos impactos da aceleração tempo-espaço no processo educativo. A determinação mais precisa desse impacto dar-se-ia pela percepção temporal. Esta se trata de um fenômeno psíquico de natureza sensorial e com dimensões subjetivas. Para Schiffman (2005) percepção é o escrutínio em função de juízos dedicados aos fenômenos sensoriais que, por sua vez, são externos ao sistema nervoso central. 
Nesse sentido, a percepção é quase como um conjunto das sensações, um contíguo de atributos sensoriais, uma categoria da mente, com toda dimensão metafórica que esta vivência comporta. Em se tratando de percepção temporal esta é multideterminada, uma vez que depende de uma série de fatores associados. Temperatura corporal, ritmos circadianos e nível de complexidade da tarefa a ser executada são algumas das variáveis que interferem na percepção de tempo. No que diz respeito ao nível de complexidade da tarefa, este, muitas vezes, está associado ao expressivo número de informações que chegam ao campo perceptual de tal forma que, segundo Coren, Ward e Enns (2004), esta relação direta torna mais evidente o efeito subjetivo da passagem de tempo.

De fato, o excesso de estímulos e do número de informações parece caracterizar o que estamos chamando aqui de sociedade do excesso: excesso de trabalho, excesso de vivências, excesso de contatos, excesso de informações e de saberes, aparentemente disponíveis. Quase como faz o bebê, instintivamente tentamos bloquear e nos defender de tal intrusão, a tempo que, ambivalentemente, somos instigados a responder à sedução de seus encantos. É importante lembrar, e aqui nos apoiamos em Flusser (2010), que o termo informação lhe diz por si do seu caráter metonímico: "in-formação", ou em formação, ou seja, informação não é sequer conhecimento, mas conhecimento em formação. Obviamente que tudo começa com a senso-percepção, o corpo-emoção, até chegar à ação humana em sua complexidade e especificidade. É o representacional que mediará no futuro a ação instrumental, praxial e voluntária dos seres humanos (VYGOTSKI, 2000; WALLON, 2008). E como nos lembra Einstein, a relatividade do tempo não é uma distorção subjetiva, mas um fato real que os sujeitos percebem e podem admitir sem cair no relativismo.

A complexidade dessa relatividade temporal dá-se conforme as modificações estruturais nas relações de produção pelas quais passou a humanidade, salienta Türcke (2014). O marco dito civilizatório do Estado nacional moderno seria justamente marcado pela maestria em perceber, fato que levou à criação de estratagemas de sempre reinventar formas de chamar a atenção para não sucumbir, pois quem não tem sensações, percebe e é percebido, não é.

Sabe-se, a partir de Bueti, Bahrami e Walsh (2008), que a percepção de tempo é um fenômeno muito complexo uma vez que envolve várias áreas corticais associadas. Pesquisar esse fenômeno também é uma tarefa complicada, conforme afirmam Bruss e Rüschendorf (2010), pois exige vários métodos de estudo a depender da grandeza de tempo que se queira avaliar. Pesquisas relativas a grandezas temporais na ordem de milissegundos ou segundos, exigem abordagens diferentes se comparadas com grandezas relativas a meses ou mesmo anos. A primeira dificuldade a ser superada é a de que não há como objetivamente aumentar a velocidade do tempo, mas tão somente avaliar alteração de percepção e seus efeitos subjetivos.

É justamente nesta última perspectiva que se insere nossa problemática. Trata-se da dimensão mais subjetiva associada ao tempo e que muitas vezes, envolve subestimação ou superestimação dos intervalos temporais objetivos. É o campo dos significados e a dimensão simbólica da experiência temporal que estão atrelados aos mais diversos fenômenos cotidianos e que devem ser analisado no que diz respeito à associação com a necessidade de atividade, conceito importante que emerge da sociabilidade atual e que queremos aqui demonstrar. 
Tal necessidade, sob o viés psíquico, insere-se na perspectiva sintomatológica como formas de atender às condições contemporâneas de circularidade intensiva da informação. $O$ primeiro modo corresponde justamente ao consumo de marcas dado o caráter de fetiche que se atrela à mercadoria, conforme Marx (2008), no seu confronto ao obsoletismo programado das marcas (SEVERIANO, 2007). O esvaecimento do objeto e da marca impõem ao sujeito a necessidade de uma rápida substituição. É óbvio que o capitalismo contemporâneo se utiliza de importantes descobertas psicológicas: um objeto não é apenas um objeto na realidade, mas o é porque é um objeto para um sujeito, ele mesmo passível de objetação, em uma relação social de onde tudo, no fundo, emergiu. O sujeito humano não só vê objetos, mas ele próprio pode se objetar. Trata-se daquilo que Mead, conforme citado por Farr (2004), descreveu como a passagem para o simbólico característico da especificidade humana. Corresponde justamente à passagem do ato comunicativo em geral para o ato linguístico tipicamente humano, a possibilidade de se colocar projetivamente no lugar do outro, se objetar para um outro em termos inicialmente significante para um significado.

A esse respeito, do ponto de vista subjetivo, afirma Türcke (2014) que mesmo que haja uma necessidade simbólica ligada à mercadoria na condição de coisa inanimada, tal necessidade já está lá como um dado a priori, uma vez que foi o mercado que alçou o objeto à condição de mercadoria necessária e consequente provocadora de necessidade.

Por outro lado, temos as marcas que os capitalistas sabiamente percebem como produtos que impactam os sujeitos, que lhes marcam. São produtos reais, objetivos, mas cujo valor depende especialmente da marca psicológica que causam. Eis o deslocamento produzido pela sociedade das mercadorias: valores de uso, marcas de pura sobrevivência e necessidade são deslocadas para marcas sociais mais complexas que podem ser trocadas por, radicalmente, qualquer coisa, tais como marcas psicológicas gerais, culturais, que aparentemente substituem as necessidades e a elas não se reduzem.

No campo da educação isto se torna mais notório pela lógica do consumo de ideias e pelo produtivismo, dito intelectual, a ele associado. Isto está representado pelo trabalhador-pesquisador que, segundo Machado e Bianchetti (2011), tem o desafio da "desfetichização" do produtivismo acadêmico. De igual modo isto se aplica também ao campo da educação básica e superior uma vez que a necessidade de atividade está atrelada ao constante aprendizado das recentes conquistas intelectuais e sua vã promessa de felicidade. Do ponto de vista dos estudantes e aprendizes a própria formação profissional se torna ela mesma um produto a ser consumido, mas agora em um apelo excessivo, como a mercadoria da qual não podem prescindir para serem quem gostariam de ser e assim serem reconhecidos.

$\mathrm{Na}$ esteira dessa primeira forma de correspondência a essa demanda social, está a ideia de necessária e premente formação continuada como constante adaptação às solicitações promovidas pela sociedade da informação. Trata-se, isto, da segunda forma de lidar com a sociedade do excesso. Destacam-se, nas palavras de Veen e Vrakking (2006), características essenciais de comportamento da net generation marcada pela sua suposta capacidade de executar múltiplas tarefas, determinar núcleos essenciais das informações e pela aprendizagem colaborativa. A justificativa dessa determinação de conduta ampara-se na ideia de que os saberes não se estabilizam mais em uma longa 
série temporal, ao mesmo tempo em que sua democratização é possibilitada pela sociedade mediada (TSATSOU, 2009).

Ora, é justamente essa dilatação de atividades aceleradas que depõe contra experiências de vida mais sadias e menos perturbadoras do ponto de vista psíquico, suas preocupações e repercussões sociais e a necessidade de proceder a uma crítica mais meticulosa, que vá à raiz da estrutura da sociabilidade contemporânea e a suas contradições. Isto se dá primeiro porque nosso sistema sensoperceptivo é seletivo e tem um limite para a quantidade de informação que teríamos condições de operar ao mesmo tempo (SCHIFFMAN, 2005); segundo porque não somos "informívoros", ou seja, não temos a capacidade de transformar informação, tal como se apresenta hoje, em conhecimento, salienta Pozo (2005). Dessa forma, conclui o autor, vivemos o paradoxo de cada vez se aprender mais ao mesmo tempo em que se fracassa mais na tentativa de aprender.

$\mathrm{O}$ aspecto mais contraditório do que estamos a discutir é que as argumentações aqui expostas pouco parecem dizer ou serem efetivamente apreendidas por todos, obviamente pela sociabilidade atual, teoricamente objeto e sujeita a tal contradição da sociedade do valor, e toda sua força metonímica-metafórica aqui rapidamente apontada. Em outros termos, não se trata de uma alienação restrita ao mundo do trabalho, mas na sua manifestação no tempo e lugar mais inesperado da sociabilidade atual: na sociedade, em seu outro viés, da desinformação, e seu excesso de informação (desnecessária) e omissão de informações (necessárias) na sua disforme manifestação como supostamente sociedade do conhecimento. No fundo, na vã suposição de uma equivalência, obviamente excessivamente ideológica, entre conhecimento e informação.

A terceira forma da vivência da compressão tempo-espaço e sua relação com a experiência de formação humana refere-se ao que Marx definiu como uma reação possível do sistema capitalista a uma queda tendencial nas taxas de lucro, inerente ao seu funcionamento (MARX, 2008). Uma reação básica e bastante utilizada é o investimento em máquinas e tecnologias, inclusive da informação, como forma de barrar essa queda. Trata-se do aumento na composição orgânica do capital e sua consequência mais direta: a necessidade de aumentar a produtividade e o ritmo do trabalho (máquinas que metonimicamente ampliam o esforço humano e metaforicamente incorporam o saber do trabalhador). Há, dessa forma, quase que a transferência do trabalho como produto da cultura humana, e de sua história formativa e educativa, ao universo das máquinas como solução mais emergente para os problemas estruturais do capital.

A quarta forma de percepção temporal e sua relação mais estreita com o contexto educativo das tecnologias digitais está conectada a um desdobramento da expressão anterior. Trata-se da redução da experiência subjetiva ao campo dos aparelhos em função da circularidade da informação e sua crescente expressão binária e digital. O que permite este aparte é justamente o caráter semiótico que se poder imputar ao campo dos aparelhos.

Flusser (2010) fez dessa angustiante análise o objeto de sua investigação ao longo de sua vida, em uma perspectiva semiótica, teórica e pragmática e politicamente "desengajada" na tentativa de decifrar o que ele denominou sociedade dos aparelhos e das imagens técnicas. A escrita produz a história ao registrar em marcas gráficas a homogeneidade mitológica da cultura oral, 
redimensionando, por meio do processo metonímico-metafórico, o sistema de representação em objetação concreta, produzindo o heterogêneo. Já o mundo das imagens técnicas, cujo precursor foi a máquina fotográfica, "des-historiciza" o mundo. As imagens não têm contorno, não têm buraco, nada lhes falta e podem ser produzidas ao infinito. Neste sentido, os sujeitos humanos não estão mais ante a máquina, como na sociedade industrial, em que esta ditava o próprio ritmo do seu trabalho e se apropriavam dos seus saberes. As máquinas contemporâneas, os aparelhos, e sua linguagem binária e computacional, entram na mente humana e interagem diretamente com ela. Cada nova geração de aparelhos se aperfeiçoa como fruto dessa interação. Somos agora seres programados pelos aparelhos, reduzindo nosso mundo ao binarismo das imagens técnicas e a-históricas, destaca Flusser (2010).

Podemos perceber que a experiência de percepção de temporalidade no contexto educativo das tecnologias digitais mostra diversas formas de expressão sendo que apresentamos algumas delas, uma vez que tais se mostram mais sintomáticas para nós. Foi justamente uma análise de cunho vivencial de nossa experiência na educação escolar e não escolar que permitiu a visualização e os afetos provocados pela sociedade dos excessos na sua "exigência" de atividade. Uma das formas mais contundentes ligadas, particularmente, à prática pedagógica é aquilo que se denominam metodologias ativas de aprendizagem ou mais exatamente um ativismo metodológico pautado na técnica e na suposta capacidade dos alunos de responder por suas próprias necessidades de aprendizagem.

Em sua origem estas estavam ligadas ao contexto do movimento de Escola Nova e seu enfrentamento à escola tradicional, esta última registrada pela passividade do aluno. $\mathrm{O}$ apelo constante pelo consumo de ideias e suas marcas ativas com fins à aprendizagem e pela formação continuada, na sempre incorporação de novos métodos ativos, levaria ao aumento da produtividade do aluno (futuro trabalhador) e sua consequente vivência no universo dos aparelhos.

Andar ou correr? O aluno já não tem mais paciência, ele quer consumir um produto pronto, em um fast food educacional em que a informação/conhecimento precisa ser acessada de forma quase que instantânea. A aula tem que ser dinâmica, nada de exposição/reflexão. É nesta lógica que há um mantra no uníssono de nossas práticas pedagógicas que reza pela manutenção dos alunos em atividade, uma vez que o exercício da reflexão, da degustação da leitura, da percepção de contraditórios das ideias é tido como arcaico, ou melhor, bizantino, nada moderno, nada ativo. Parece-nos que tudo isto se trata de uma realidade mais que presente na formação humana contemporânea e cumpre-nos, na condição de educadores, minimizar seus efeitos.

\section{CONSIDERAÇÕES FINAIS}

A educação escolar tem uma característica pendular uma vez que reflete as oscilações das conjunturas sociais na sempre tentativa de corresponder às suas exigências. É com esta leitura que nos permitimos a realização das análises aqui dispensadas, consequências de nossas reflexões intelectuais e que se faz insurgir neste breve ensaio. É nesse intuito que apresentamos neste momento algumas de nossas conclusões a partir do resgate de nossa questão inicial. Perguntamo-nos pela 
relação entre percepção temporal e necessidade de atividade no processo educativo, no atual contexto da sociedade dos excessos. Categorias destacadas por nós como essenciais para uma análise revisional da atual conjuntura de sociabilidade, sobretudo aquela vinculada à educação.

Parece-nos haver indícios de que existem algumas formas reativas perturbadoras e porque não dizer, que se aproximariam do psicopatológico, de lidar com a premente necessidade de atividade à qual estão submetidos os sujeitos da sociedade da informação. É inegável os benefícios das tecnologias de informação e comunicação aplicadas à educação, mas ficamos perplexos ao quase silêncio sobre seus entraves ou gradações possíveis entre benefícios e problemas, uma vez que não desejamos ser cooptados, de igual modo, por uma lógica binária e ideológica de análise da situação.

É nesse percurso que destacamos pelo menos quatro formas de corresponder à suposta necessidade de atividade na sociedade do excesso e seus afagos sedutores oriundos da circularidade da informação: o consumo de marcas, a formação continuada, o ritmo de trabalho e a redução da experiência subjetiva ao universo dos aparelhos. Da mesma forma que a educação se presta ao movimento pendular de quase sujeição e de quase correspondência aos ditames do contexto social, leiam-se, ao capital na atualidade, de poder, de paixão; esta teria também condições de propiciar espaços de experimentações para além da experiência mais imediata proporcionada pelas tecnologias.

Certamente que inibir os efeitos da sociedade da informação, em seu viés excessivo, seria um labor hercúleo, entretanto o ato educativo já possui outras estratégias apropriadas que poderiam minimizar os efeitos da compressão temporal. Trata-se da recorrência às artes ou qualquer outra forma de retorno às experiências sensoriais estéticas que, embora tenhamos tido grandes oportunidades de vivenciá-las nos nossos primeiros anos de vida, estas são paulatinamente, mas não decisivamente, substituídas em nossa formação, como sujeitos de sensações, percepções e criação. Pode ser uma oportunidade de percebermos que o necessário é muitas vezes desnecessário e de aprendermos a lidar com fragmentos do excesso de informação.

Por fim nos perguntaríamos sobre as necessidades de aprender e ensinar numa sociedade excessiva e dos aparelhos. Seria possível mudar a direção? Mais pode significar menos? Isto é, mais informação menos conhecimento; mais produtos e menos valores; mais trabalhos e aparelhos e menos humanidade? Ou podemos seguir a máxima modernista do arquiteto Ludwig Mies van der Rohe "menos é mais". Como retomar o exercício da reflexão e da visão metafórica e analógica do mundo para além do fascínio que o binarismo na sua simplificação parece propor?

Eis o paradoxo, a metáfora produz o novo não porque ignora a diferença, a história, ao produzir o sincrônico e o categorial e responder pela dimensão inconsciente da mente. Mas é exatamente porque tem nesses elementos sua matriz analógica que nos aponta a dimensão para além do próprio reflexo, o campo da reflexão, do pensamento como ontogenético e não uma mera gnosiologia. Afinal, a aceleração do tempo-espaço e sua compressão seriam mais um ingrediente que no ponto futuro retirariam do humano sua percepção histórica e sua capacidade de produzir o novo, logo um enorme desafio para a educação na contemporaneidade. 


\section{REFERÊNCIAS}

ADORNO, Theodor. O ensaio como forma. In: COHN, Gabriel (Org.). Theodor W. Adorno: sociologia. 2 ed. São Paulo: Ática, 1994. p. 167-187.

BUETI, Domenica; BAHRAMI, Bahador; WALSH, Vincent. Sensory and association cortex in time perception. Journal of Cognitive Neuroscience, Massachusetts, v. 20, n. 6. 2008. Disponível em < http://goo.gl/dJonlS > Acesso em: 07 mai. 2014. ISSN 1530-8898.

BRUSS, Franz Thomas; RÜSCHENDORF, Ludger. On the perception of time. Gerontology, Basel, v. 56, n. 4. 2010. Disponível em < http://goo.gl/3XXhYf > Acesso em: 08 mai. 2015. ISSN 03230003.

CASTORIADIS, Cornelius. As encruzilhadas do labirinto. Rio de Janeiro: Paz e Terra, 1987. $335 \mathrm{p}$.

CHAVES, Hamilton Viana; MEDEIROS, Márcia Duarte. O pensamento na era das tecnologias digitais, Conexões: Ciência e Tecnologia, Fortaleza, CE, v. 10, n. 1. 2010. Disponível em <http://goo.gl/uBZs2w> Acesso em: 08 mai. 2015. ISSN 2176-0144.

CORDEIRO, Alexandre Magno; OLIVEIRA, Glória Maria de; RENTERÍA, Juan Miguel; GUIMARÃES, Carlos Alberto. Revisão sistemática: uma revisão narrativa, Revista do Colégio Brasileiro de Cirurgiões, Rio de Janeiro, RJ, v. 34, n. 6. 2007. Disponível em: <http://goo.gl/5C9hQr> Acesso em: 11 jan. 2015. ISSN 1809-4546.

COREN, Stanley; WARD, Lawrence; ENNS, James. Sensation and perception. New Jersey: Wiley, 2004. $613 \mathrm{p}$.

FARR, Robert. As raízes da psicologia social moderna: 1872-1954. Petrópolis: Vozes, 2004. $246 \mathrm{p}$.

FLUSSER, Vilém. A escrita: há futuro para a escrita? São Paulo: Annablume, 2010. 180 p.

HARVEY, David. Condição pós-moderna: uma pesquisa sobre as origens da mudança cultural. São Paulo: Loyola, 2000. 349 p.

MACHADO, Ana Maria Netto; BIANCHETTI, Lucídio. (Des)fetichização do produtivismo acadêmico: desafios para o trabalhador-pesquisador. RAE - Revista de Administração de Empresas, São Paulo, SP, v. 51, n. 3. mai./jun. 2011. Disponível em 〈http://goo.gl/dWV1zr $>$ Acesso em: 10 jul 2015. ISSN 2178-938X. 
MAIA FILHO, Osterne Nonato; CHAVES, Hamilton Viana; RIBEIRO, Luís Távora Furtado; SOUSA, Natália Dias de. O impacto da aceleração tempo-espaço nos modos de produção. Cadernos de Pesquisa, São Luiz, MA, v. 21, n. 2. 2014. Disponível em 〈http://goo.gl/909Zku> Acesso em: 03 fev 2015. ISSN 2178-2229.

MARX, Karl. O capital. vol. 1. Tomo 1. 25. ed. Rio de Janeiro: Civilização Brasileira, 2008. 579 p.

MOURA, Diego Luz; SOUSA, Clayton Batista. A utilização de novas tecnologias em uma escola experimental do Rio de Janeiro. ETD - Educação Temática Digital, Campinas, SP, v. 16, n. 2. mai./ago. 2014. Disponível em <https://goo.gl/A6wgF1> Acesso em: 07 mai. 2015. ISSN 16762592.

PEIRCE, Charles Sanders. Semiótica. 3 ed. São Paulo: Perspectiva, 2005. 337 p.

PERROTA, Carlo. Do school-level factors influence the educational benefits of digital technology? A critical analysis of teachers' perceptions. British Journal of Educational Technology, London, v. 44, n. 2. 2014. Disponível em <http://goo.gl/AtwELh> Acesso em: 07 mai. 2015. ISSN 1467-8535.

POZO, Juan Ignácio. Aquisição de conhecimento: quando a carne se faz verbo. Porto Alegre: Artmed, 2005. 239 p.

REY, Fernando Luís González. Pesquisa qualitativa em psicologia: caminhos e desafios. São Paulo: Pioneira Thompson Learning, 2002. 188 p.

SCHAFF, Adam. A sociedade informática: as consequências sociais da segunda revolução industrial. São Paulo: UNESP, 1990. 157 p.

SCHIFFMAN, Harvey Richard. Sensação e percepção. 5. ed. Rio de Janeiro: LTC, 2005. 419 p.

SEVERIANO, Maria de Fátima Vieira. Narcisismo e publicidade: uma análise psicossocial dos ideais do consumo na contemporaneidade. São Paulo: Annablume, 2007. 377 p.

TRIGANO, Philippe. Self-regulated learning in a TELE at the Université de Technologie de Compiègne: an analysis from multiple perspectives. European Journal of Education, Paris, v. 41, n. 3/4. 2006. Disponível em <http://goo.gl/00gnP2> Acesso em: 23 set. 2013. ISSN 1465-3435.

TSATSOU, Panayiota. Reconceptualising 'time' and 'space' in the era of electronic media and communications. Journal of Media and Communication, Melbourne, v. 1, s/n. 2009. Disponível em <https://goo.gl/ATGL28> Acesso em: 07 mai. 2015. ISSN 2141-8545.

TÜRCKE, Christoph. Sociedade excitada: filosofia da sensação. Campinas: Editora da Unicamp, 2014. $323 \mathrm{p}$. 
VEEN, Win; VRAKKING, Ben. Homo Zappiens: growing up in a digital age. London: Network Continuum Education, 2006. 160 p.

VYGOTSKI, Lev Semionovich. Obras escogidas, problemas del desarrollo de la psique. 2 ed. Tomo III. Madrid: Visor, 2000. 381 p.

WALLON, Henri. Do ato ao pensamento. Petrópolis: Vozes, 2008. 224 p.

ZIMMERMAN, Barry. Self-regulated learning and academic achievement: an overview.

Educational Psychologist, London, v. 25, n. 1. 1990. Disponível em: 〈http://goo.gl/ItKX8Z〉 Acesso em: 03 mar. 2013. ISSN 1532-6985.

\section{Como citar este documento:}

CHAVES, Hamilton Viana; MAIA FILHO, Osterne Nonato. Percepção de tempo e necessidade de atividade na sociedade do excesso: educação no contexto das tecnologias digitais. ETD - Educação Temática Digital, Campinas, SP, v. 18, n. 1, p. 71-82, abr. 2016. ISSN 1676-2592. Disponível em: <http://periodicos.sbu.unicamp.br/ojs/index.php/etd/article/view/8635719>. Acesso em: 05 abr. 2016. doi: 〈http://dx.doi.org/10.20396/etd.v18i1.8635719>. 